$2^{\text {nd }}$ World Conference On Future Of EDUCATION

BRUSSELS, BELGIUM

11-13 September 2020

\title{
Training and Knowledge of Parents of Children with Diabetes Mellitus
}

\author{
Emilia Georgieva, Petya Trendafilova* \\ Medical University - Sofia, Faculty of Public Health, Department of Health Care, Sofia, Bulgaria \\ *Corresponding author
}

\begin{abstract}
.
Diabetes mellitus (DM) is a socially significant non-communicable disease due to emerging complications, disability, premature mortality. It also requires large financial costs due to lifelong expensive treatment, the need for constant monitoring and related diagnostic tests and periodic hospitalization [1]. In Bulgaria, the annual incidence varies from 7 to 9 per 100,000 with a proven in recent years linear dependence of growth of about $4.4 \%$ per year, most pronounced in the older age group, but also in the age group of 5- and 9-years old children [2]. A pilot survey was conducted among 60 parents of children with diabetes from all over the country, hospitalized in "Specialized hospital for active treatment of children's diseases - Prof. Dr. Ivan Mitev" EAD - Sofia". The knowledge and training of the parents are analyzed. The results show that $2 / 3$ of them are trained on the daily monitoring of their children, the signs and symptoms of hypoglycaemia and hyperglycaemia, daily care, diet and exercise. More than half of parents confess that families with diabetes children need constant help and support from qualified and trained medical professionals. Despite the ongoing training of parents of children with diabetes, only one third of the respondents are considered fully trained in almost all elements of child care.
\end{abstract}

Keywords: diabetes mellitus, children, hypo and hyperglycaemia, training, diet and exercise. 


\title{
$2^{\text {nd }}$ World Conference On Future Of EDUCATION
}

\author{
BRUSSELS, BELGIUM
}

11-13 September 2020

\section{Introduction}

Diabetes mellitus (DM) is a socially significant non-communicable disease due to emerging complications, disability, premature mortality. It also requires large financial costs due to lifelong expensive treatment, the need for constant monitoring and related diagnostic tests and periodic hospitalization (Георгиева, 2017, Ем.).

Type 1 diabetes accounts for $10 \%$ of the incidence, but it is the most common type of diabetes in children and young adults - $90 \%$ of cases of diabetes mellitus among Caucasians in this age group. Every year the incidence of type 1 diabetes increases by about $3 \%$ and more often under the age of 15 years. The number of newly diagnosed children in this group is expected to increase annually by about 86,000 .

In Bulgaria, the annual incidence varies from 7 to 9 per 100,000 with a proven in recent years linear dependence of growth of about $4.4 \%$ per year, most pronounced in the older age group, but also in the age group of 5- and 9-years old children (Георгиева, 2020, М.).

Training family members on the health of children with diabetes is an important element of child care and a guarantee of good metabolic control. It aims to create specific knowledge, habits and behavior of parents for a balanced diet, proper exercise, medication, control, etc.

\section{Methods}

A direct individual pilot survey was conducted among 60 parents of children with diabetes, hospitalized in "Specialized hospital for active treatment of children's diseases - Prof. Dr. Ivan Mitev" EAD - Sofia" in 2020. A questionnaire was prepared and tested for this purpose. The aim is to study parents' knowledge about caring for their children. Logical units of observation are the parents of the children, technical unit - the specified medical institution for hospital care. Alternative and graphical statistical analysis was used in the processing of the information.

\section{Results and Discussion}

The distribution of parents by age groups shows that $2 / 3$ of them (40 persons) are in the age group 30-39 years, 8 are in the group 21 to 29 years, 6 parents - over 40 years of age and for 6 persons there is missing data.

The distribution of children shows that from 2 to 5 years there are 24 children, from 6 to 10 years - 28 children, 4 children are over 10 years and for 2 children there is no data. Therefore, most of the observed hospitalized children are in the age group 2 to 10 years.

The therapeutic maxim includes insulin, diet, physical activity and self-control training. This treatment lasts a lifetime and parents should know this at the time of diagnosis. The goal of treatment is to achieve good metabolic control, which ensures a normal style and quality of life, optimal conditions for growth and development, maximum protection from acute complications of the disease and removal of vascular lesions (Георгиева, 2020, М.). 


\section{$2^{\text {nd }}$ World Conference On Future Of EDUCATION}

\section{BRUSSELS, BELGIUM}

An individual care plan is prepared for each patient, including:

- continuous education and support of patients and their families

- constant assessment for acute complications - hypoglycaemia or hyperglycaemia

- assessment of chronic complications - neurological, ocular, renal, cerebrovascular, cardiovascular

- Routine monitoring with: multiple daily blood sugar measurements using a glucometer or through the systems for continuous glucose monitoring / Free Style Libre, Enlite, Dexcom and others. /; measurement of glycated hemoglobin (Hbalc) every 3 months

The education of patients and their relatives is a very important and significant function of health professionals. The training can be focused on the ways of carrying out the treatment prescribed by a doctor, the observance of the nutritious diet, what physical activity to observe at the diagnosis, etc. Through the training of family members contributes to the adaptation of patients and their loved ones to their condition or disease, providing or maintaining maximum comfort, avoiding or reducing health risk factors, changing lifestyles to healthier ones. (Воденичаров \& Попова, 2010)

As a rule, the training of the parents of children with diabetes is carried out by qualified specialists in training centers established at the medical establishments. (Димитрова, 2019, A.) (Dimitrova, 2019, A.)

The results of the survey regarding the training of parents for the daily monitoring of their children show that $2 / 3$ of the parents are trained - 40 people. 23 of them believe that they are fully trained and 17 - only partially. It is worrying that $1 / 3$ of the parents indicate that they do not have enough knowledge to perform such an observation (Fig. 1).

Figure 1: Distribution of parents according to their training for the daily observation of the child

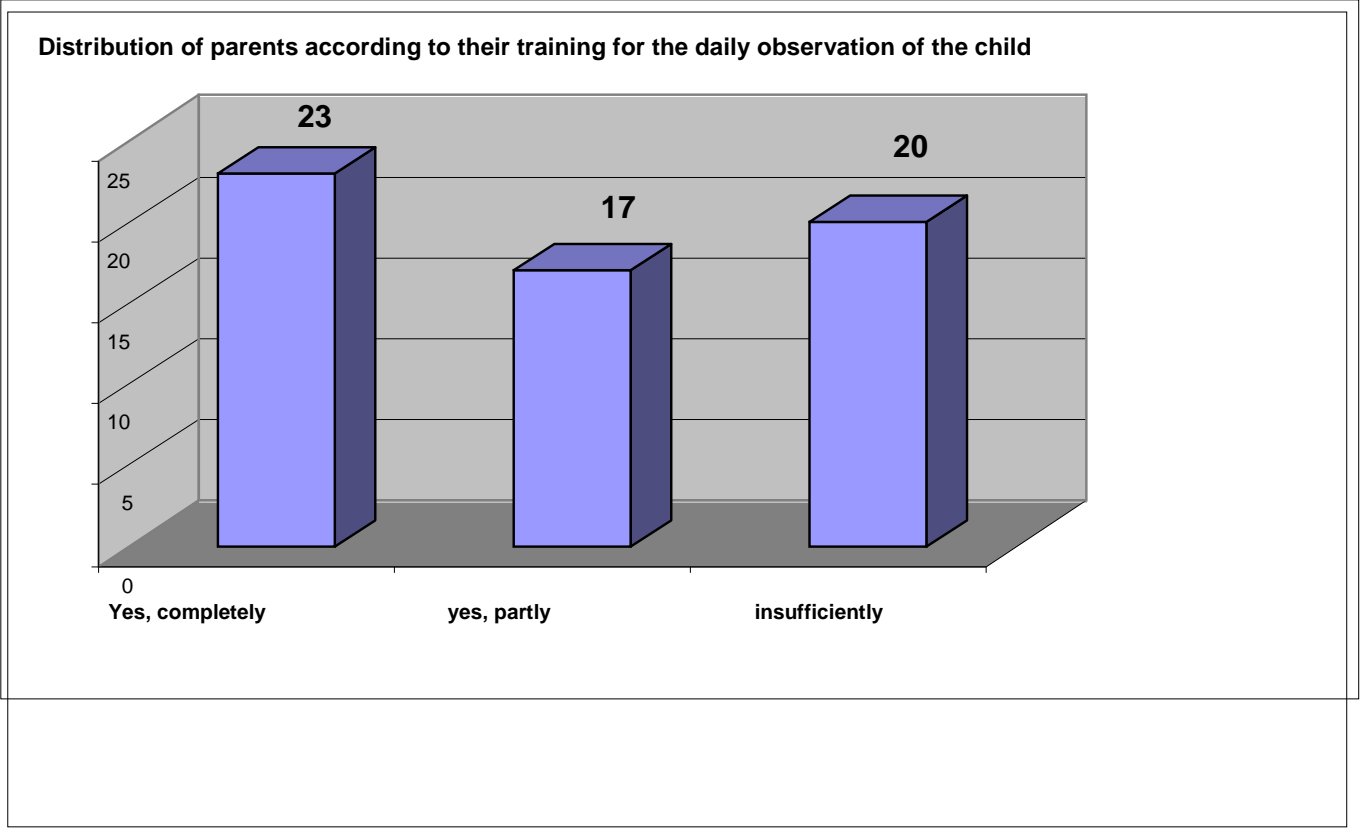




\title{
$2^{\text {nd }}$ World Conference On Future Of EDUCATION
}

\author{
BRUSSELS, BELGIUM
}

11-13 September 2020

Knowledge of the signs of hypo- and hyperglycaemia is extremely important for disease control. 20 parents are fully aware of the signs and symptoms of hypoglycaemia, in part - 24 parents a considerable number - 16 people do not know enough about the symptoms of this condition.

24 parents are fully aware of the signs of hyperglycaemia, 21 partially and again 15 people do not know enough about its symptoms.

Only 14 parents are fully trained in the behavior and decisions to be made in a child with hypoglycaemia, 16 are only partially trained and the majority of them - 29 people indicate that they are not trained enough.

The results are almost the same for the behavior of hyperglycaemia. Again, only 14 parents are fully trained, 28 - partially and 18 - insufficiently trained.

Children with diabetes require constant daily care. However, the data show that only 10 of the surveyed parents are fully trained to know and provide such care, 32 people are trained only partially and 18 - insufficiently (Fig. 2).

Figure 2: Distribution of the respondents regarding their training for the daily care of the child

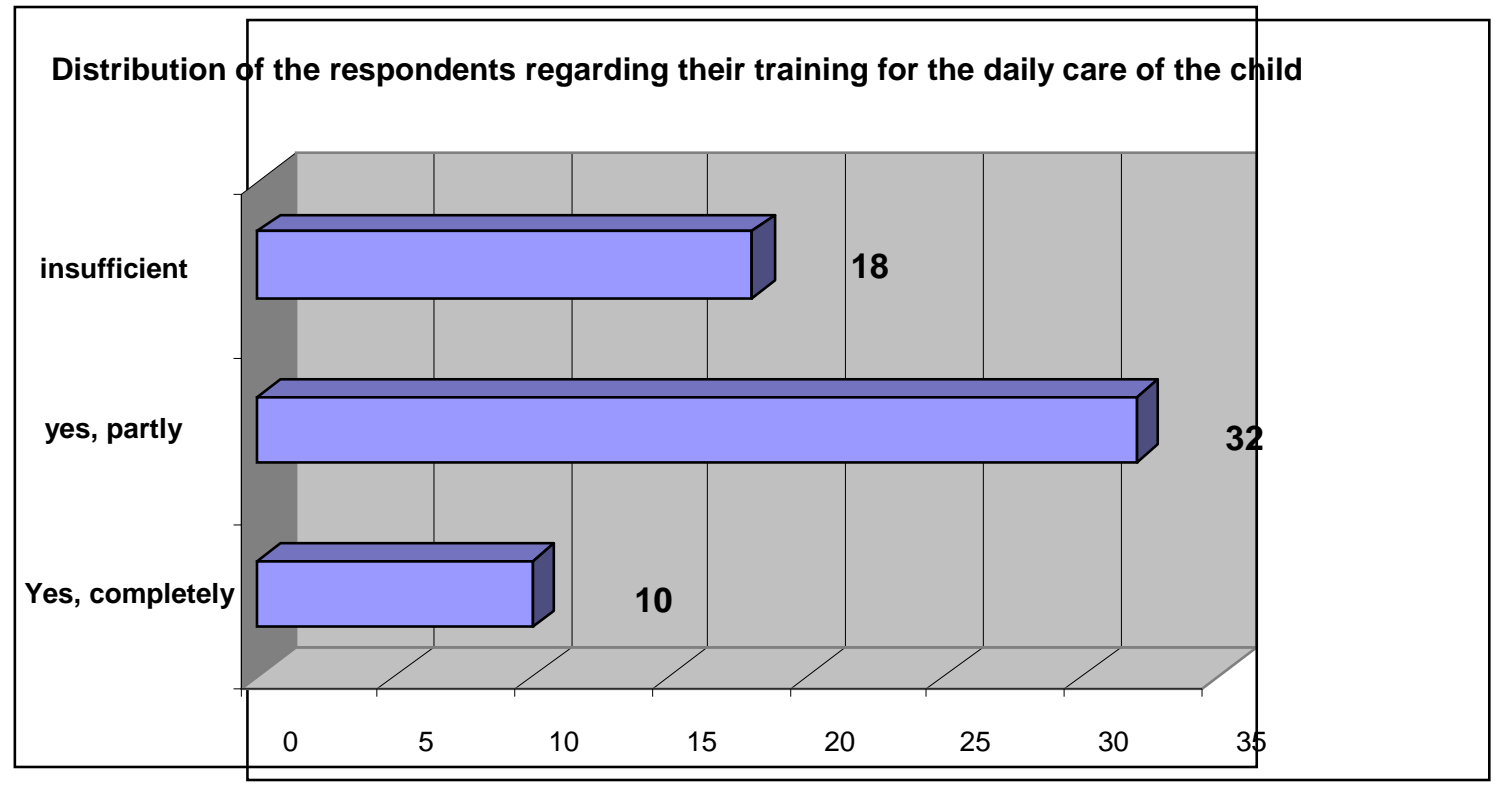

Daily care also includes knowledge about children's diet and strict adherence to it. Again, only 10 respondents feel fully trained to control their diet, 32 - only partially and 18 insufficient.

Difficulties in complying with the diet in providing food are encountered by 12 respondents, in control and self-control of the child - 24, due to misunderstanding by relatives - 6 people. One third of parents ( 22 people) indicate that they need qualified specialists to support the family in this problem.

In addition to the diet, a guarantee for optimal metabolism is the observance of the motor regime by children. Only 13 respondents indicated that they had provided a completely 


\section{$2^{\text {nd }}$ World Conference On Future Of EDUCATION}

\section{BRUSSELS, BELGIUM}

appropriate motor regime for their children, 32 - partially and 8 - insufficiently. As reasons for this, 24 parents consider the lack of specialists to work with children with diabetes and 13 lack of conditions for motor development - mainly lack of time and perseverance. One third of the respondents do not encounter difficulties in ensuring optimal motor mode.

The most important element of caring for a child with diabetes is conducting insulin treatment. (Dimitrova, 2018, A.) The further course of the disease, the occurrence of complications, admission to hospital, etc. also depend on this. (Dimitrova, A. \& M. Dimitrova, 2019). Parents should be well trained in when and how to administer insulin. However, the data show that only 17 are fully trained, 24 - partially and 29 respondents (more than a third of parents) are not considered prepared (Fig. 3).

Figure 3: Distribution of the respondents depending on their training for insulin treatment

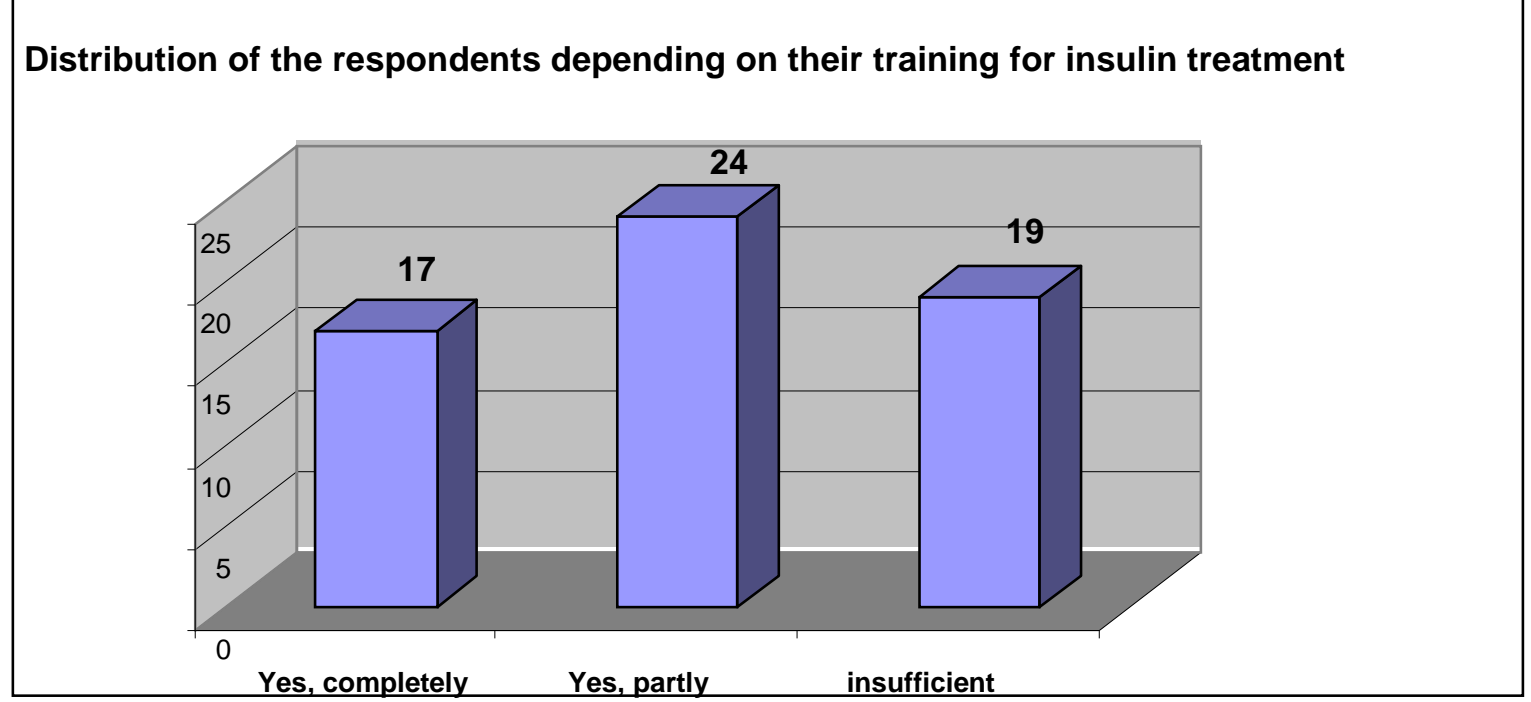

At the same time, only 9 people have difficulties in providing medicines and consumables, 35 - sometimes 16 do not have such difficulties.

In general, more than $2 / 3$ of the respondents (43 people) believe that it is necessary to provide continuous help and support to the families of children with diabetes by qualified and trained medical professionals. The majority of respondents indicate that they need more information and additional training.

\section{Conclusion}

Despite the ongoing training of parents of children with diabetes, only one third of the respondents are considered fully trained in almost all elements of child care.

It is necessary to raise the awareness of the family and appropriate, according to the age of the children, health education. The requirements for families are determined by the social, medical and pedagogical requirements related to learning about the health of adolescents and the formation of a new type of health behavior. 


\title{
$2^{\text {nd }}$ World Conference On Future Of EDUCATION
}

\author{
BRUSSELS, BELGIUM
}

11-13 September 2020

The need of the modern family to create appropriate conditions and opportunities for increasing their health knowledge and turning them into motives, and respectively into healthresponsible behavior, is growing.

It is important to study in more depth the problems of families in the care of children with diabetes. The participation of various specialists in their upbringing is an opportunity to help parents in solving various problem situations and, above all, to prevent complications and deviations in the proper development of the child. In this regard, the nurse, who has a professional qualification, has a significant role to play in assessing the needs for care and offering the family care plans that will ensure the necessary quality of life regardless of the child's chronic illness.

\section{References}

1. Георгиева, Ем. (2017). Социално-медищински и психологични проблеми при хронично болни пациенти (деиа и подрастващи), дис., С.

2. Георгиева, М. (2020). Захарен диабет при деца и юноши. http://drmgeorgieva.com

3. Воденичаров, Ц., С. Попова. (2010). Медицинска етика, С.

4. Димитрова, А. (2019). Мениджмънт на грижите при изгаряне, ISBN 978-6197491-10-4, ЦМБ, МУ-София.

5. Dimitrova, A. (2019). Necessity of professional competence of healthcare specialists at the treatment of patients with burns. International journal Knowledge ISSN 25454439 ISSN 1857- 923X, Global Impact \& Quality factor 1,822/2017/, Vol. 30.4, Serbia, march 2019, pp 931-937

6. Dimitrova, Anushka. (2018). Standard behavior and care in recurrent period of patients after burns. International journal Knowledge ISSN 2545-4439 ISSN $1857-$ 923X, vol. 26,4 Greece 2018, pp 1189

7. Dimitrova, A., M.Dimitrova. (2019). Parents ' information needs about the risk and gravity of burning injury. Knowledge International journal ISSN 2545-4439 ISSN 1857- 923X, Vol. 34.№ 4, Skopje, september 30, 2019, pp 1089-1094. 